Excellence in Performing Arts Research

Volume 2

2015

Taking Charge: Looking at Student Leadership in the High School Band Room

Darren S. LeBeau

This paper won the Award for Excellence in Graduate Research, Honorable Mention, 2014-15.

\title{
Citation Elements
}

LeBeau, Darren S. (2015). Taking Charge: Looking at Student Leadership in the High School Band Room. Excellence in Performing Arts Research Vol. 2 doi: 10.21038/epar.2014.0106. Retrieved from https:/oaks.kent.edu/epar/vol2/iss1/taking-charge-looking-student-leadership-high-school-band-room 


\begin{abstract}
This qualitative action research case study examines the experiences of three band students in an American high school. The participants took leadership roles in a large performing ensemble. Their overall experience may be affected by this additional responsibility. To understand more about the role of leadership in the band room the following research questions were investigated: (1) How has student participation in a leadership role influenced his or her view of the band? (2) What are the influences that impact student participation in the band? (3) What are the implications for leadership roles in the band? Three individual students were purposefully selected to participate in this case study. Students were interviewed, and then combined in a focus group and finally observed working with their sections. Individual interviews and the focus group discussion was recorded, transcribed and entered into NVivo. Codes and themes were identified and referenced for common threads and concepts. The goal of this study was to understand and assist the future training of leaders in the band setting.
\end{abstract}

\title{
Introduction
}

The typical marching band and concert band has a hierarchy of student leadership to help the director manage the band program. This hierarchy has always been around and can be labeled closely with the distributed leadership model, which will be discussed later in this paper. In a current search of literature, the development of this hierarchy system was not found, even though bands have a student leadership system of some form in place. Leadership can be handled in a number of ways in a band program. Over the years, my leadership system has evolved as my band program has grown. There is a wide variety of levels for student motivation in our band. A student can be very motivated to work hard, help the younger members to learn to march and learn music, or they can be in band for just the social aspect and be content to be a follower.

The concept of student leadership is to have the members of the group become invested in the success of the program through their direct input. This idea of leadership has only come into play in recent years for my band because I felt the students were not fulfilling my expectations in the area performance goals. The ownership of these performance goals through the setting and execution of goals is one avenue to have student input. When the band was smaller in number, the proportion of self-motivated students was higher and outnumbered the purely social students. The leadership team was incorporated to give all students a direct line to the success of the program.

Students are capable of making decisions concerning band through their involvement in the process. There needs to be a better understanding for the student leaders, directors and followers to work together to meet their shared goals. Warfield (2013) stated that leadership in the twenty-first century has shifted to allow the students to take more ownership in band and allow them to have a say in some of the decisionmaking. With a new understanding of the roles each member of a band plays, a better experience can come forth while creating music in the marching band genre. 


\section{Purpose and Need for the Study}

The purpose of this action research case study is to investigate the effect on the student in a leadership role within the band. The leadership team has been only been instituted this past year and there is a need to find out if being in the new leadership role has a positive or negative experience for those members. Through this discovery, the leadership team training may be improved to make the experience better for the members in these roles. The hope is to continue to develop the positive aspects of student leadership and lessen the negative aspects.

\section{Scope of the Research}

The scope of this action research case study is contained within my band program. Three students were purposefully selected because of their prior roles as leaders in the band program. The investigation looked at a student who had planned and worked to be the head student leader though his role as a section leader and squad leader the previous two years. One participant worked his way from the ranks of freshman to senior and had the musical talent and maturity to handle his section. Finally, a student was selected because the next in line of seniority for a leadership role left the band program. This inexperienced student was not prepared to move up to a leadership role until the next year, but had to prematurely.

\section{Definitions}

Through the course of this study, these terms may be used to describe roles within the hierarchy of the band. The level of expectation increases depending on the role the student has earned.

Leadership Team - a group of students in the band program who have worked on their leadership skills through an after school workshops program the previous spring. All students had at least one year of high school band before learning how to become a student leader. The leadership team is made up of all section leaders, squad leaders and band council members.

Section Leader - a student selected to lead an instrument family. Candidates have a level of maturity, musical talent and possibly seniority in their section and participated in the spring leadership program the previous year. Section leaders are in charge of music and marching basics for their section member.

Squad Leader - a student who is in charge of a squad consisting of four total members within an instrument family. A squad leader makes sure that their three members learn the marching maneuvers on the field or in parade block. Squad leaders may be younger members of the band such as a junior or senior not yet ready for the role of section leader. Squad leaders assist the section leader in the leadership duties.

Band Council - a group of students who are elected by their peers to help manage the band activities. There is a president, vice president, treasurer, secretary and four class representatives. The band council organizes fundraising, social events, activities for band camp and the yearly banquets. Council is a direct link between the 
band director and the general band member. Because the band council is elected by the band membership, they may or may not be part of the leadership team.

\section{Limitations}

This case study only looked at the experience in this band program and could have different results in other bands with alternative leadership training ideas and hierarchies. The experiences of these three students may not be the same for the others section leaders in the band. Since these were high school students, care was taken to make sure they felt comfortable and safe answering questions. Some sections are more mature overall and have more self-motivated students and others could have a level of higher social orientated students, which can have implications on the overall band experience in a positive or negative manner. Similarly, the students interviewed may not clearly elaborate in full thought out phrases to get here ideas across.

\section{Research Questions}

When creating the research questions, keywords such as view, influence, and implication were used to focus the experience of the leadership role. This action research case study used the following research questions: (1) How has student participation in a leadership role influenced his or her view of the band? (2) What are the influences that impact student participation in the band? (3) What are the implications for leadership roles in the band?

\section{Methodology}

The goal of this project was to investigate the effects that leadership roles in the band have on the individual and the overall band experience. The band is a group of individuals who work together as one ensemble to create music. The success of the band depends on the members working together for common goals.

\section{Plan of Research}

The method used for this study was an action research case study. According to Gay, Mills and Airasian (2009), action research is a systematic inquiry conducted by teachers, principals, school counselors, or other stake holders in the teaching-learning environment to gather information about the way in which their particular school operate, the teachers teach, and the students learn. To focus this action research, it was combined with the methodology of case study. Gay et al. defined case study as the in-depth investigation of one unit, individual, group, institution, organization, or program. Yin (2009) defined case study as a research method to contribute to our knowledge of individual, group, organizational, social, political, and related phenomena.

Once the method was selected, Institutional Review Board approval was completed after the appropriate forms and documentation was submitted to the Office of Compliance. To begin the process, participants received letters to invite them to be a 
participant. Each study participant received an individual assent form after the participating letter was signed, as well as a consent letter for their parents to sign.

Once all letters where returned, each participant was interviewed privately and recorded on a $\mathrm{H} 4$ digital recorder for transcription and coded using NVivo, a qualitative coding software, for analysis. Interview questions were selected for the anticipatory set of questions submitted at the time of IRB approval. Because of the short preparation time for IRB approval, this case study used anticipatory questions from Melton's study (2012). The interviews were conducted at the end of class in the privacy of the band room. All three participants were then combined into a focus group to further elaborate on five questions pulled from the individual interviews the following week. To clarify, a focus group is a type if interview that brings participants together to discuss the phenomenon researched (Palys \& Atchison, 2008).

The participants were all section leaders within the band. Each was observed leading sectionals on new music being rehearsed for the next concert to add a third source of data. These observations and field notes were used to identify and view the interaction between the participants and their sections in a rehearsal setting. It was noted that the more mature sections handled instruction from the section leader with respect and attention to detail. They handled correction and truly attempted to improve for the section leader. However, the immature section handled sectional time as time off. Their section leader taught the parts like the others but the section had poor posture, talked between instructions and did not attempt to fix mistakes. Using multiple data collection methods increased the legitimacy and trustworthiness of the results.

The researcher used a digital recording device to collect data. Participants consented to digital recording of the focus group and individual interviews. I uploaded the recordings to my computer and they are stored in a separate file. The researcher transcribed the data and sent transcripts for a member check to the participants who confirmed their validity. Participant were numbered and all names where removed from the transcripts after validation. Themes were created from the data collected from the focus group and individual interviews and by reviewing the transcripts multiple times and entering data into the NVivo program, which assisted in identified codes, ideas and patterns for each participant and theme.

\section{Literature review}

A marching band student leader instructs students and leads them to complete and understand goals that have been set by the band director and the leadership team. Some goals are music related, and other goals focus on marching technique and some administrative aspects of leadership as well. According to Warfield (2013), the existing literature on music leadership in not substantial, but helped guide this study. In examining the lineage of leadership literature, Rost (1991) suggest that as generations differ from one to the next, the perception of leadership also seems to change. While finding a leadership theory to explain all styles of leadership seems impossible, with each research study something new is uncovered in the quest for defining an effective leader (Warfield, 2013). 


\section{Distributive Leadership}

Student leadership is an important part of a band. Without student leadership, the staff would have to manage all of the students personally. Warfield (2013) found that distributive leadership best defines the style of leadership in most band programs. This model applied to a marching band could explain how student leaders, band directors, assistant directors and followers work together and adjust the leadership roles depending on varying situations.

Spillane, Halverson and Diamond (2001) defined distributive leadership according to the situation and how the leaders of the organization execute their duties. Situations are defined as routines, tools, and structures that determine the leadership practice of an organization. The theory described an organizational structure of multiple leaders of small groups with tasks assigned to the smaller groups. A marching band relies on multiple leaders and student leaders for each section. A marching band relies on these leaders to lead their small group throughout rehearsal, performances, and other activities. It would be difficult for a band director to correct every band member on step accuracy, instrument angle, instrument carriage, coordinates, and other marching techniques.

Student leaders are believed to be an essential part of many musical ensembles. Lautzenheiser (2002) states, "Student leaders are not a luxury, but a necessity, therefore the selection, training and guidance of these young leaders is a crucially important aspect of every band director's daily responsibility" (p. 97). The need for student leaders is influenced by the size of the ensemble, the task that needs to be accomplished, and the amount of time available.

\section{Leadership Style}

A recent study (Melton, 2012) examined bullying between student leaders and non-student leaders in two urban high school marching bands. The author interviewed four student leaders and four non-student leaders and concluded that non-student leaders experienced some bullying from student leaders during their marching band experience. The experience the student has as either leader or non-leader is the focus of this study. The literature found does focus on the negative impact of student leaders using bullying to get their job done. The balance between student leaders guiding and instructing verses bullying a student to get work done will affect the experience of both the student leader and the non-leader. I hope to make sure student leaders continue to learn to skills to carry out there role without oppressing the followers.

Melton (2012) indicated four concerns when examining student leadership in the marching band: 1) Leaders did not follow through with responsibilities; 2) leaders bullied others; 3) leaders were affected by the pressures of the job; and, 4) leaders dealt with being a public figure as part of their job. An effective student leader in a marching band organization should not bully the students, but instead show appreciation and celebrate with followers. If a student leader does not have the approval of the student followers, it will be difficult to be an effective leader according to Warfield (2013).

Leadership studies in music education demonstrate the need for effective student leaders in music ensembles. Research indicated that being a successful leader required more than music skills (Teachout, 1997, 2001). Music skills are important for a marching 
band student leader. They must also oversee an instrument section, teach marching fundamentals and drill.

To date, no studies have examined the distributive leadership model in marching band organizations (Warfield, 2013). It is reasonable to assume that there is a connection between marching band organizations and the practice of distributive leadership, because collegiate marching bands organizations often have large numbers and multiple levels of leaders to assist in the operations of the organization. The marching band director often distributes leadership responsibilities to others within the organization similar to high school marching bands. This study examined how the student leadership experience was affected personally.

Student leadership in marching band plays an important role in respective organizations. When selecting leaders, a band director must be certain he or she is choosing someone who will not only follow commands and relay them to the section, but also someone who will take some initiative and be a leader when he or she sees or hears problems in the band.

According to Warfield (2013), research on leadership in music examines the experienced music educator or university students preparing to go into the field of music education and not leadership within a high school band. None of the literature provided perspective from everyone involved in the organization. It is important that the leaders perform duties as a leader at their best. Kouzes and Posner (1987) stated behaviors of student leaders and responders perception of such behaviors determine their effectiveness in an organization.

\section{Participant Description}

The three interviewed participants were purposefully selected from the existing leadership team. The team members consist of high school band members who attended workshops the previous spring and were selected and performed the duties of section leader and/or squad leader.

\section{Participant 1 (Larry)}

Larry has been a member of the music program since fifth grade and has been in the high school band all four years. He is currently preparing to major in music performance after high school graduation. This member of the leadership team has progressively taken on the role of leader as he has participated in the band program. As a freshman he followed the leadership that was in place. He was awarded a squad leader position his sophomore year and he was the section leader his junior year over a senior. Because of his musical abilities and maturity he has been very successful in the music program. Because of his sense of loyalty and understanding of leadership, he worked to be selected as the drum major. This participant's experience with his section was different because, overall, it was very mature and musically strong. 


\section{Participant 2 (Curly)}

In contrast to the first participant, Curly has come through the band program in a very immature section. He too has been in the music program since fifth grade and has gradually taken on leadership roles as he has gained experience during his high school years. This student is very mature and musically strong. The section of which this participant is a member has traditionally been male dominated and very immature. However, it has also been a very important part of the success within the marching band Participant 2 has had very strong role models to emulate as he was growing up through the ranks of the section. He used this experience to guide his section to the best of their abilities.

\section{Participant 3 (Moe)}

The third and final participant was prematurely thrown into the role of leader. The upperclassman in line of succession for the role of leadership left the music program. Moe did not have the luxury of having another year to observe the section prior to taking over. This member of the leadership team has also been in the music program since fifth grade. Moe is not as strong musically as her counterparts, but wanted her section to do well. It follows that her moving up to the role also meant that her section was much younger and immature overall. This section of the band was the most immature in the band. Even though Curly's section had an immature section his section understood they had to get certain things done and had a tradition to uphold. In contrast, her section was immature and had no sense of understanding of their role or their responsibility in the band (Figure 1):
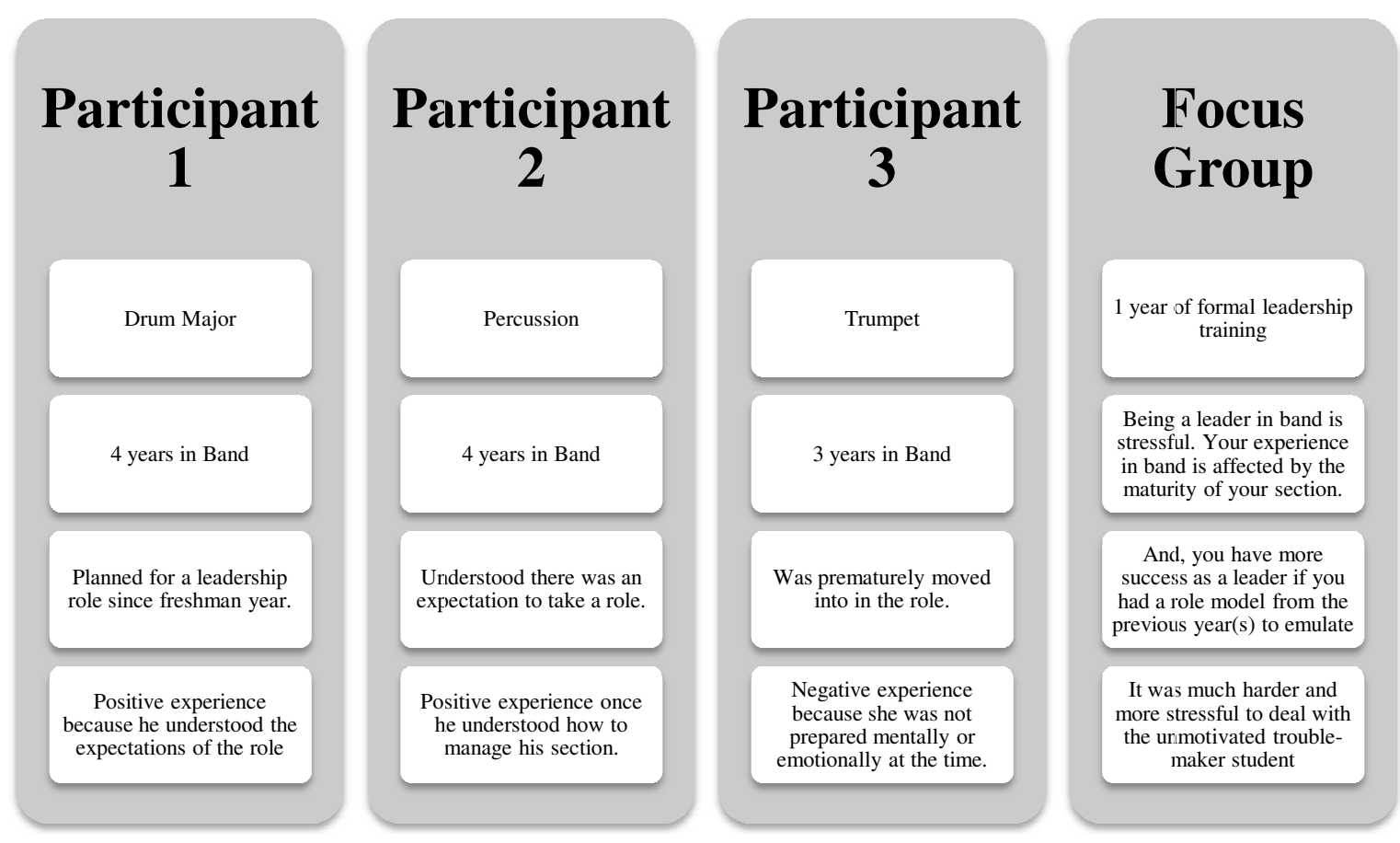

Figure 1. Participant Comparisons 


\section{Data}

The overarching research questions guiding this case study were: How has student participation in a leadership role influenced his or her view of the band? What are the influences that impact student participation in the band? What are the implications for leadership roles in the band? I chose to focus the data analysis on the view, influences, and implications of being in a leadership role.

Through the reading of the data collected from the interviews and the focus group and observations, a number of themes came into view: (1) Being a leader in band is stressful. (2) Experience in band is affected by the maturity of the section. (3) Leaders have more success if they had role models from the previous year(s) to emulate. From these themes, key words such as, alumni, respect, motivation, immaturity resonated from all three participants and in the focus group. It broke down in the following manner (Figure 2):
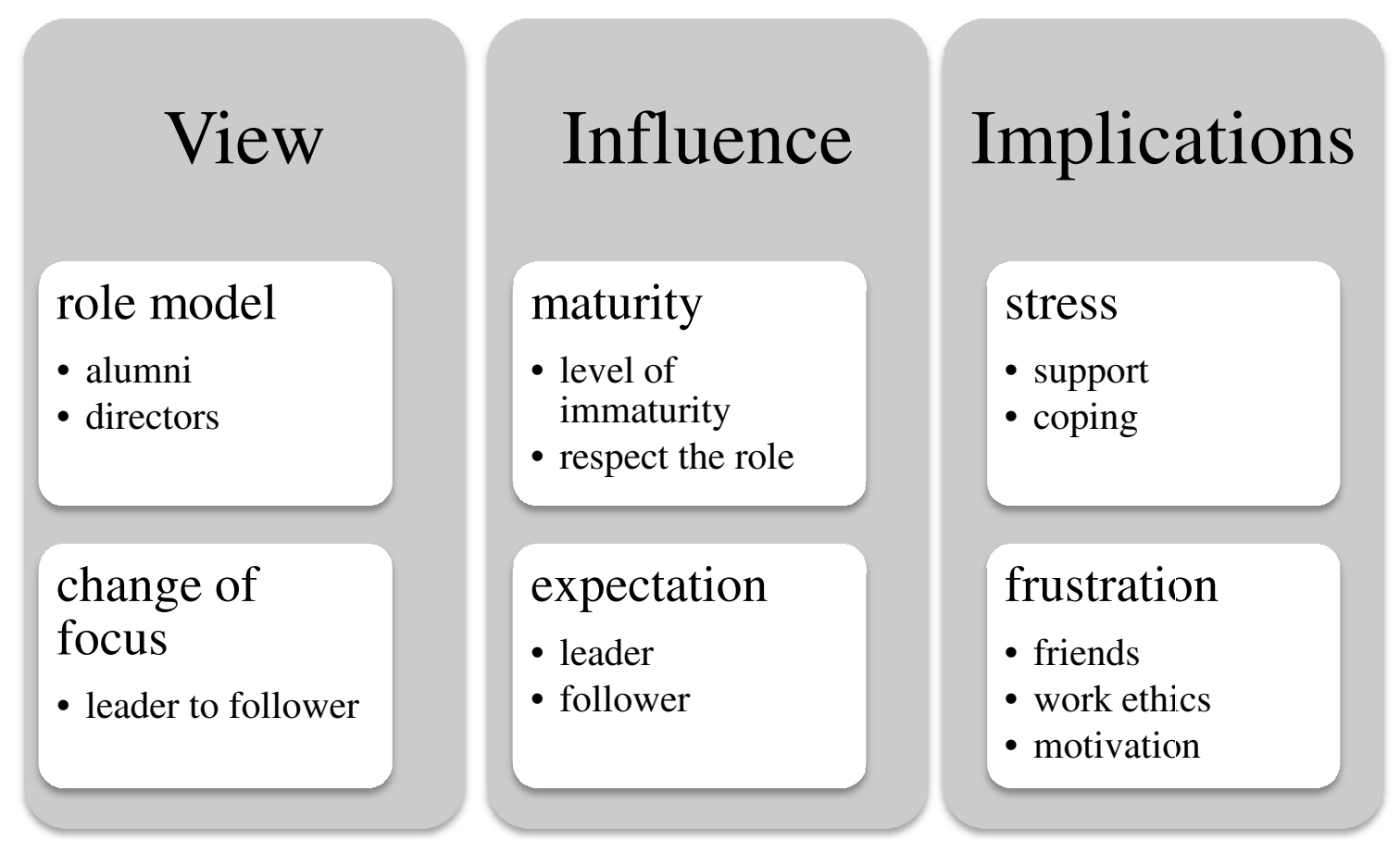

Figure 2. Keywords

The level of maturity of each study participant influenced and related to the level of stress each of them experienced while being a leader. The participant Larry, who is the most mature, felt that if he was leading by example, stayed calm, showed his peers that he cared through his actions, and kept his emotions in check. Then, he did not feel the leadership role had undo stress. He came into this role understanding that he was capable of doing his job and that he could handle the responsibility. "I take what I do very seriously, so I think that other people can look at me and think, 'Okay, he really cares about what he does, maybe we should start to think like that too." He was selected by his directors and earned their trust that he would do the right things for the band. 
The student who had to take over a section because the leaders in line decided not to continue in the band program interpreted the level of stress differently. The participant Moe was thrown into the role unexpectedly. Moe stated, "There really [weren't] any seniors, I just kind of felt like there wasn't anyone else up to it." The stress level was heightened because the maturity in the same section was not at the same level as the rest of the band. This participant felt the lack of experience in the leadership role and the immaturity of the section was frustrating.

There are expectations from the director that certain things should get done by section leaders and squad leaders. The stress level emerged as the section was not following the instruction of the leaders, did not have the maturity to handle instruction from peers, and did not have self-motivation to learn key elements on their own. This immaturity led to conflicts between the section leader and the members of that section as well as the rest of the band.

Curiously, the section leader who had the notoriously immature section was still able to carry out the duties in this leadership role. He used the term managed to define his leadership technique. He understood that the role of section leader was going to be stressful and there was not a way of getting around the fact he had a bunch of rough guys. However, the guys had to work together for the betterment of the band. Like the first participant, he came to band knowing the expectations of the directors and the job he was to do. Curly said, "I think the student leaders, especially in marching band should be motivated and positive." She also stated, "It can be hard sometimes, we are always willing to push harder, and be critical of our underlings, but not to the extent of ... hurting them." At the beginning of the season his level of stress was higher until he found out how to mange his section, which was to spread the duties of section leader to others in the group to make them more accountable for the success of the group as a whole.

For all participants the level of stress ebbed and flowed throughout the season. During the discussion in the focus group, the participants felt the need to have the section take ownership for their success. The participants agreed with Larry when he stated, "Probably the biggest challenge of any part of being student leaders is trying to get those people that just seem like they do not want to be here to try to participate." If students were motivated to be actively involved in the final product the stress level would not be as high. They felt the stress level increased as they saw the expectations of the directors grow through the season. They also had members of their sections progressing at the same pace.

It was understood that there was going to be stress when you are expected to take on the role of student leader. Each participant coped with the stress in different ways. Curly found a secluded place and listened to music to decompress, while Moe complained to her mother after practice. Larry walked away, using his yoga skills to relax. Each of the interviewed felt they could take any situation to the directors and ask for assistance. All participants would try to handle the situation first by talking directly to the person(s) creating the stress. At times these students would be handed the responsibility to solve the situation themselves so they could understand why it was stressful for the student leader. However, it really depended on the level of maturity of the person needing to be brought back into line. It is very hard to make someone do anything. They need to want to improve or be involved. 
The idea of seclusion was one of the coping mechanisms these three leaders used along with talking it out with their peers. Learning to walk away, finding some alone time and not taking it personally were all used in some form by the participants over the course of the season. The leaders believed that the stress would not go away. As such, the experience in band would be negatively affected if they did not know how to release some of that stress as the season progressed. They also referenced their role models as examples of how to handle stress.

There was emphasis on the theme of role model throughout the interviews and in the focus group. Interestingly, the role model theme was used to emulate section leaders from their previous years as they themselves served as role models for their own sections. The two participants who had an understanding of the stress level that came along with student leadership stated specific characteristics they saw in leaders when they were younger. They discussed alumni with great respect and reverence. The alumni were a positive influence on their personal experience and they wanted it to carry on through their own legacies as well.

On the other hand, the third participant, who had been a wide-eyed freshman, did not see what the leaders were really doing in their roles before taking over as leader the next year. When it was time to be in the leadership role, there was a level of inexperience that the others did not have. Her view of the leaders from her past was "[j]ust because you are a good marcher does not mean you are a good leader or [able to be] in charge."

Emerging from the focus group, the data was mainly focused on the trouble student. The participants were asked to address more on the interview question about the role of being a leader though expectations of the role and the director. They all agreed that the role model should be a positive example for others to follow by leading from example. In this lively conversation they felt there were students who just could not be led. These trouble students did not understand how their behavior affected students all around them and how the resulting final product would not represent their best effort. According to Moe, "One particular member that I tried to work with on marching over and over again, I took him to the drum major and he still would not do it. I backed off and he never did get it because he was not willing to listen."

Interestingly, the conversation about the trouble student led to the second question: What drew you to the leadership role? For the group, the positive influence of a role model led them to the role. They felt they could create a positive experience for all the members and they all would work to be their best. The trouble student just needed the right guidance. The combination of their role models and their ideas of leadership was the answer to getting everyone working together. But, however, they found this was really not the case. It was much harder and more stressful to deal with the unmotivated trouble student.

To return to the research question keywords: The participants in this study found their view of the band to be different than the rest of the membership. They discovered as leader, there are students who were involved for just the social aspects; not the performance or musical aspects of the performing group. They also found that they could not make someone do something he or she did not want to do. The participants chose to be active in band for musical and social reasons, so their early involvement with their role models developed a more positive view of leadership. When they stepped into the role, 
they found not all members were created the same, which collided with their personal ideas of why someone should be in the band.

The influences impacting the student were identified as the single influence: the level of maturity. This was addressed in both the focus group and observed in sectionals. It took them some time during the early days of the season to understand they also could not make someone mature before their time. They learned to work with the limitations of the immature students, but it added stress to the role because the participants had expectations and goals. The lower level of maturity interfered with the progress of their sections.

The lack of maturity led to the answering of the third research question that asked for implications for leadership roles in band. The implication of being a leader in band is that it adds a level of stress while participating. The trouble students added to the stress frustrating leaders, which in turn affected relationships with their peers. It also strained their friendships with other members who are or were their friends.

\section{Implications for Practice}

The three research questions that guided this study were to identify the view, influence and implications concerning the role of leadership in the band. The word maturity was strongly stated many times and in many contexts. The understanding that a person cannot make someone do something he or she does not want to do can also be applied to the concept of maturity: A person cannot make some mature before their time. The implication for practice is how the stress of the role is handled, knowing there are students at various levels of maturity, as well as levels of commitment to the band.

If the student leaders and the band directors both recognize there are those unmotivated and immature students in the band, then focus needs to be on how to handle those kind of students. The literature identified the hierarchy of a band leadership organization (Melton, 2008, p. 8) and the need for this framework of leadership. Melton identified the role of the leader and slightly touched on the role of the follower (Warfield, 2013 , p. 12). For the level of stress to lower, the leadership team should bring the level of understanding of the follower up to the expectations of the leaders.

It would seem to reason, if there is a group of students electing to take on roles of leaders, there should be a process for the followers in the band as well. Leaders are trained by exposing them to the responsibility of the role through the following factors: viewing educational videos of authority figures in student leadership, having discussions of implications in their current band organization, and role playing to help them understand how to be leaders. There are also interviews and workshops to develop a sense of caring and support for the team and the band.

These same concepts should be used on the followers of the band. The focus group expressed that followers did not seem to understand that there are expectation for them as well. Much time is spent training the student leader and very little time is focused on the training of the followers. The non-leaders should be writing a one-page essay on the following topics: "What is my role as a member of the band?" and "What are the expectations of the students not on the leadership team?" It is clearly important to take the time to have discussions with the followers on how they can help the leadership team succeed with meeting the goals that the group developed. Followers can also play the role 
of leader. This role reversal may help the follower see the negative impact his or her behavior has on the band. Students leaders have been indoctrinated in the ideas and philosophies of the band directors, but many times the followers are at the mercy of guessing what is expected of them.

Rush (2003) set forth a framework to build student leadership. He proposed that the qualities that constitute an effective teacher are the qualities that band directors are looking for in our student leaders. Students must understand that they are part of a larger team and may need to sacrifice personal conveniences for the betterment of the whole. True teamwork is very powerful and its principles are quite simple, but actually achieving it is as rare as a valuable gemstone (Rush, 2003, p. 93).

\section{Conclusion}

This study sought to answer the general question: "What is the effect on the student experience when in a leadership role in band?" The study sought to uncover the experience the leaders had in band through their view of the band, the influences that are present and the implications of being a leader.

The study interviewed three students from the marching band who were members of the leadership team. They were interviewed using questions to find out how they viewed aspects of the experience being a leader and what expectations were placed upon them. These leaders related that the experience was positive but found frustration with the unmotivated band student. Leaders could not understand why any member of the band would not want to do their best and succeed at meeting developmental goals and musical skills by working together for a successful marching band season.

In summation, student leadership is definitely important to the functioning of a band program. Student leaders help the band director with many tasks within a program, and those tasks vary from band to band. However, student leaders are given many tasks to handle, and how they handle those tasks are largely left up to the student leader. Whether they handle it positively and calmly or negatively and forcefully, that is the power that student leaders gain when their director gives them a title of leader.

Leadership is obviously very stressful as indicated by the students interviewed. By taking time to listen to what they experienced we as researchers, advisors, teachers, coaches or adults are better equipped to assist the student leader in having a positive experience. The adult leaders should create a culture where young leaders and followers openly discuss any situations and understand the implications of unwanted behaviors that create stress. They should provide the student leaders with the tools to handle stress in a mature and consistent manner.

Through this study it was clear that there are two sides to every story. When developing a leadership team it was obvious there was a need to expose the members to responsibilities of leadership and gain knowledge to help them lead their sections. On the other hand, there is also a need to develop a training program for the follower, to help him or her understand what the leaders are trying to do. 


\section{References}

Conner, J. O. \& Strobel, K. (2007). Leadership development: An examination of Individual and programmatic growth. Journal of Adolescent Research. (22)3. 275-297.

Gay, L. R., Mills, G. E., \& Airasian, P. W. (2009). Educational research: Competencies for analysis and applications. Upper Saddle River, New Jersey: Pearson Educational Inc.

Gooty, J (2009). In the eyes of the beholder. Journal of Leadership \& Organizational studies. (15)4. 353-367.

Kouzes, J. M., \& Posner, B. Z. (1987). The student leadership challenge: How to get extraordinary things done in organizations. San Francisco, CA: Jossey-Bass.

Lautzenheiser, T. (2002). The selection and development of effective student leaders. Teaching Music through Performance in Band Volume 4 (pp. 97-108). Chicago, IL: GIA Publication Inc.

Logue, C. T., Hutchens, T.A. \& Hector, M. A. (2005). Student leadership: A phenomenological exploration of postsecondary experiences. Journal of College Student Development. (46)4. 393-408.

Melton, Curtis, J. (2012). Facing the music: Student relations in student leadership with in high school band programs. (Doctoral dissertation). Available ProQuest Dissertation and Theses database. (UMI No. 3553658)

Palys, T. \& Atchison, C. (2007). Research decisions: Qualitative and quantitative perspective. ( $4^{\text {th }}$ ed.). Canada: Nelson Education Limited.

Rost, J.C. (1991). Leadership for the twenty-first century. New York, NY: Praeger Publishers.

Rush, S. (2003). Habits of a successful band director. Fort Wayne, IN: Focus on Excellence.

Spillane, J. P. Halverson, R., \& Diamond, J. B. (2001). Investigating school leadership practice: A distributed perspective. Educational Researcher. 30(3), 23-28.

Teachout, D. J. (1997). Pre-service and experienced teacher's opinion of skills and behaviors important to successful music teaching. Journal of Research in Music Education, 45(1). 41-50.

Teachout, D. J. (2001). The relationship between personality and the teaching effectiveness of music student teachers. Psychology of Music, 29(2), 179-192.

Wallin, D. (2003). Student leadership and democratic schools: A case study. NASSP Bulletin (87) No. 36. 55-77.

Warfield, Duane A. (2013). Perception of student section leaders in selected collegiate marching band. (Doctoral dissertation). Available ProQuest Dissertation and Theses database. (UMI No. 3608799).

Yin, R. K. (2009). Case study research: Design and methods $\left(4^{\text {th }}\right.$.ed.). Thousand Oaks, CA: Sage Publication. 


\section{Appendix}

\section{Anticipatory Interview Questions}

1. How long have you been involved in the band program?

2. What instrument do you play?

3. Did you hold any leadership positions in middle school band? In any other organization?

4. How long have you been a student leader in this band?

5. Describe in as much detail as possible, what you think the role is of a student leader within a band program.

a. Do you feel as a leader, that you have met those expectations?

b. How have you met those expectations?

c. Did the director specify those roles or are those your personal opinion?

6. Elaborate and explain, what does your director expect you to do as a student leader; what jobs must you undertake?

7. Describe the specific instance that drew you to the leadership team for a leadership position within this band program.

8. What does your director do to support you as leader, and is there a support system in place for you as a leader?

9. Are there pressures of this job?

a. Describe how you cope with the/any pressure(s) of the job.

10 . Do you think you are respected by your peers as a leader?

a. Describe how you can tell that is.

11. Do you feel that you have ever been bossy to your peers?

a. Has there ever been a time where you had to "assert" your authority?

12. What "freedom" do you have to enforce rules?

a. Do you give special treatment to your friends?

13. Describe how you deal with "difficult" section members who just will not listen to you.

a. Have you lost friends because of being in a leadership position?

b. Why do you think that is?

c. What kinds of power do you try to use to influence the person who is being difficult?

14. Has any problem from someone in band towards you "bled" over to your other classes or outside of school or online? (i.e. Facebook, Twitter, or text)

a. Have you witnessed this happening to others?

15 . With the current system of leadership in place within your program, what do you feel the band community is like?

a. Describe what it is like to walk into the band room every day.

16. As a result, do you feel constantly under stress or relaxed when you are around your peers and your band director?

17. Describe a time where you feel you successfully led other people.

18. Overall, do you think student leadership is important to a band, or does it hinder the organization?

19. Is there anything that you feel that needs to be addressed and/or clarified in regards to anything we have talked about? 


\section{Adapted from:}

Melton, C. J. (2012). Facing the music: Student relations in student leadership with in high school band programs. (Doctoral dissertation). Retrieved from ProQuest Dissertations and Theses. (UMI 3553658) 